\title{
Atividade antioxidante e captora de radicais livres dos extratos de Achyrocline alata (Kunth.) DC. em comparação com extratos de Achyrocline satureioides (Lam.) DC.
}

\author{
Rafaela F. Grassi-Zampieron, ${ }^{1}$ Maria C. Vieira, ${ }^{2}$ João M. de Siqueira ${ }^{3 *}$ \\ ${ }^{1}$ Laboratório de Farmacognosia, Departamento de Farmácia-Bioquímica, Centro de Ciências Biológicas e da \\ Saúde, Universidade Federal de Mato Grosso do Sul, CP 549, 79070-900 Campo Grande, MS, Brasil \\ ${ }^{2}$ Faculdade de Ciências Agrárias, Universidade Federal da Grande Dourados,. CP 533, Rodovia Dourados a \\ Ithaum, km 12, 79804-970 Dourados-MS, Brasil \\ ${ }^{3}$ Universidade Federal de São João Del Rei, Campus Centro-Oeste Dona Lindu, Rua Sebastião Gonçalves \\ Coelho, 400, 35501-296 Divinópolis-MG, Brasil
}

\begin{abstract}
RESUMO: Achyrocline alata (Kunth.) DC. e Achyrocline satureioides (Lam.) DC., espécies pertencentes à família Asteraceae, são utilizadas na medicina popular de Campo Grande, Mato Grosso do Sul, como plantas sucedâneas. O presente trabalho teve com objetivo comparar os extratos obtidos dessas espécies através de ensaios químicos simples destinados a testar as atividades antioxidante e captora de radicais livres, utilizando como modelo $\beta$-caroteno e DPPH, respectivamente. Tais ensaios revelaram que os extratos de $A$. satureioides foram mais ativos como captores de radicais livres do que os extratos obtidos de A. alata. Todos os experimentos foram feitos em triplicata, utilizando quercetina como padrão.
\end{abstract}

Unitermos: Achyrocline alata, Achyrocline satureioides, Asteraceae, antioxidante, DPPH, $\beta$-caroteno.

\begin{abstract}
Antioxidant and free radical scavenging effects in extracts of the Achyrocline alata (Kunth) DC. in comparison with the extracts of the Achyrocline satureioides (LAM.) DC." Achyrocline alata (Kunth.) DC. and Achyrocline satureioides (Lam.) DC. are species belonging to the family Asteraceae widely used in the folk medicine of Campo Grande, Mato Grosso do Sul, being considered substitute plants. The present work aimed to compare the obtained extracts of these species to simple chemical assays, in order to test the antioxidant activity and free radical scavenging, using $\beta$-carotene and DPPH as reference, respectively. With these assays it was observed that the obtained extracts of Achyrocline satureioides were more active, as free radical scavenging, than the same obtained extracts of Achyrocline alata. These chemical assays were compared to a known patterned, quercetin, and and they were dealt under triplicate basis.
\end{abstract}

Keywords: Achyrocline alata, Achyrocline satureioides, Asteraceae, antioxidant, DPPH, $\beta$-carotene.

\section{INTRODUÇÃO}

O gênero Achyrocline (Less.) DC., Asteraceae, inclui cerca de trinta espécies distribuídas em regiões tropicais e subtropicais, não só no Brasil como também nas Américas do Sul e Central e na África, incluindo Madagascar (Bremer et al., 1994). Na América do Sul são encontradas $A$. alata, A. tomentosa, A. flaccida e $A$. satureioides (Souza, 2002; Sonaglio, 1987).

Destas espécies, a Achyrocline alata (Kunth.) DC. é citada como uma das seis plantas medicinais mais utilizadas na medicina popular em Campo Grande, Mato Grosso do Sul (Nunes et al., 2003), onde é conhecida popularmente como "jateí-kaá". Essa espécie, juntamente com outra do mesmo gênero é muito comum no Brasil e países vizinhos - Achyrocline satureioides (Lam.) DC., conhecida popularmente como "macela" -, são utilizadas de forma indistinta, sendo a primeira considerada sucedânea desta última (Nunes et al., 2003; Vendruscolo et al., 2005).

Investigações químicas de ambas as espécies, publicados anteriormente, resultaram no isolamento de diferentes flavonóides (Broussalis et al., 1988; 1993) e sesquiterpenos (Bohlman et al., 1980). No entanto, somente $A$. satureioides foi estudada sob o ponto de vista farmacológico, e seu extrato aquoso apresentou atividades antiinflamatória e analgésica e efeito sedativo, prestandose também ao tratamento de disfunções gastrintestinais, devido a suas atividades hepatoprotetora e antiespasmódica (Kadarian et al., 2002; Simões et al., 1988). Fachinetto 
et al. (2007) verificaram atividade anti-proliferativa e citotóxica desta espécie, sobre o ciclo celular de Allium cepa indicando seu potencial terapêutico. A. satureioides foi também avaliada, revelando significativa atividade antioxidante in vitro (Desmarchelier et al., 1998). Entretanto, tanto o extrato acetato de etila de A. alata como A. satureioides não apresentaram atividade antimalárica quando testados em ratos infectados pelo Plasmodium berghei (Mariath et al., 2009).

O objetivo no presente trabalho foi traçar um perfil comparativo das capacidades captora de radicais livres e antioxidante das duas espécies e, desse modo, obter parâmetros de avaliação que permitissem justificar a substituição de uma espécie pela outra, já que ambas são utilizadas indistintamente na medicina popular sulmato-grossense. Diversos modelos já foram propostos para a avaliação prévia de substâncias e extratos vegetais com possível atividade antioxidante e captora de radicais. No presente trabalho foi utilizado ensaios químicos por autografia envolvendo $\beta$-caroteno e o radical 2,2-difenil1-picril-hidrazila (radical-DPPH), seguidos de avaliação quantitativa com DDPH por espectrometria (Cavin et al., 1998a,b).

\section{MATERIAL E MÉTODOS}

\section{Material vegetal}

Inflorescências de $A$. alata e de $A$. satureioides (Asteraceae) foram coletadas em Dourados, MS, no campus da UFMS, Brasil, em abril de 2002. A identificação botânica foi realizada por Lílian Auler Mentz e amostras foram depositadas no Herbário CGMS, do Laboratório de Botânica, CCBS, UFMS, Campo Grande, MS, Brasil, sob números 11486 e 11 487, respectivamente. As inflorescências foram submetidas a secagem com ventilação e, posteriormente, trituradas e tamisadas (Tamis Mesh 9).

\section{Extratos}

Para comparar as atividades antioxidante e captora de radicais livres de $A$. alata (AA) e $A$. satureioides (AS), foram inicialmente preparados extratos aquosos (EAQUAA e EAQU-AS). Para a obtenção de cada extrato, adicionaram-se $100 \mathrm{~mL}$ de água fervente a $5 \mathrm{~g}$ da droga vegetal, mantendo-se a mistura em recipiente fechado por $20 \mathrm{~min}$ e, em seguida, filtrando-a. O infuso resultante foi liofilizado (Lemos-Senna et al., 1997; Desmachelier et al., 1998). Outros extratos e preparações de droga vegetal foram obtidos: diclorometânicos (EDCM-AA e EDCM-AS), cada um deles preparado com $5 \mathrm{~g}$ da droga vegetal em $50 \mathrm{~mL}$ de solvente, sendo a mistura mantida em recipiente fechado em temperatura ambiente, e então filtrada e concentrada em rotavapor. À torta resultante de cada extrato diclorometânico foram adicionados $50 \mathrm{~mL}$ de metanol, e após 24 horas as misturas foram filtrados e concentrados (EMeOH-AA e EMeOH-AS) (Desmachelier et al., 1998). Além desses, a tintura preparada pelo processo de percolação, ou seja, maceração com etanol 70\% GL por $6 \mathrm{~h}$ ao abrigo da luz, seguida de extração (gotejamento a $1 \mathrm{~mL} / \mathrm{min}$ ), até se obter uma solução a $20 \%$ p/v em etanol $70^{\circ}$ GL (Farmacopéia Brasileira, 1988) (TINT-AA e TINTAS).

\section{Atividade antioxidante}

Ensaio de autografia em CCD: Para o ensaio da atividade antioxidante desenvolveu-se metodologia semelhante à proposta na literatura (Bouchet et al., 1998; Cavin et al., 1998a). para a cromatografia em camada delgada (CCD) foram utilizadas placas 20×20 de sílica-gel (Merck) eluídas em solventes apropriados aos extratos. Os cromatogramas resultantes foram então autografados com solução de $\beta$-caroteno a $0,05 \%$ (Sigma) em clorofórmio (Merck) e submetidos a radiação de $254 \mathrm{~nm}$ (utilizando um aparato de lâmpadas germicidas de $8 \mathrm{~W}$ e $16 \mathrm{~W}$ desenvolvido para o presente trabalho) até se observar descoloração do fundo da placa (De Siqueira, 2002).

\section{Atividade Captora de Radicais Livres}

Ensaio de autografia em CCD: Para avaliar a atividade captora de radicais livres (Aldrich) foi empregada a técnica de CCD acima descrita, utilizando solução de DPPH a 0,2\% em MeOH como revelador (Cavin et al., 1988a,b). A placa, depois de revelada, foi submetida exposição a radiação de $254 \mathrm{~nm}$ (utilizando o aparato acima mencionado) até se observarem manchas de coloração amarela (extratos) sobre fundo púrpura (DPPH).

Ensaio espectrofotométrico: Realizou-se também um ensaio quantitativo com DPPH a $0,02 \%$ em MeOH. Para tanto, a solução de DPPH foi adicionada à solução-teste e a leitura foi realizada após $30 \mathrm{~min}$ em espectrofotômetro com comprimento de onda de $517 \mathrm{~nm}$ (Braca et al., 2002). Os extratos foram testados em seis concentrações diferentes $(0,34 \mathrm{~g} / \mathrm{L} ; 0,86 \mathrm{~g} / \mathrm{L} ; 1,30 \mathrm{~g} / \mathrm{L} ; 1,70 \mathrm{~g} / \mathrm{L} ; 3,40 \mathrm{~g} / \mathrm{L} ; 34,00$ $\mathrm{g} / \mathrm{L})$ e em triplicata para cada concentração.

\section{RESULTADOS}

A propriedade antioxidante de cada extratos $(1 \mu \mathrm{g})$ foi avaliada por autografia com $\beta$-caroteno. Os extratos EAQU-AA, EAQU-AS, EMeOH-AA, EMeOHAS, TINT-AA e TINT-AS mostraram ação protetora sobre $\beta$-caroteno, enquanto EDCM-AA e EDCM-AS não se mostraram ativos.

Para a atividade captora de radicais livres foi utilizado o radical DPPH (cor violeta, no visível), que é um radical estável, mas que, ao sofrer adição de $\mathrm{H}$ radical, por exemplo, a partir de substâncias doadoras (Pryor, 1986), passa a apresentar cor amarelada. Por sua estabilidade e 
simples manipulação e por prestar-se facilmente para detectar a reação de terminação de radical, devido à mudança de cor, o radical DPPH tem sido amplamente utilizado para estudo monitorado por autografia e quantificação do potencial de captação de radicais livres de extratos, frações e substâncias isoladas de plantas medicinais.

No monitoramento de extratos por autografia, uma solução de radical DPPH foi borrifada sobre a placa de CCD com extratos eluídos $(1 \mu \mathrm{g})$, os quais se apresentaram ativos, como indicado pela mudança de cor prontamente detectável a olho nu (coloração amarelada, típica da reação de terminação desse radical, contra fundo púrpura, indicador de presença do radical ativo).

Pelo ensaio quantitativo, realizado por método espectrométrico, os extratos foram avaliados em seis concentrações diferentes, em triplicada, comparados a quercetina (Braca et al., 2002). Essa atividade foi determinada através da capacidade de descoloração que cada extrato apresentou sobre a solução de radical DPPH em comparação com a capacidade de descoloração da quercetina. Tal capacidade de descoloração foi determinada com o seguinte cálculo:

Capacidade de descoloração $(\%)=\left(1-\frac{\text { Abs. A - Abs. BA }}{\text { Abs. B }}\right) \times 100$

No qual a $A b s$. $A$ é a absorvância do extrato testado com a solução de DPPH $(0,02 \% \mathrm{em} \mathrm{MeOH}), A b s$. $B A$ é a absorvância do extrato em metanol e $A b s . B$ é a absorvância do branco (0,02\% de DPPH em metanol).

$\mathrm{O}$ modelo utilizado no presente trabalho permitiu comparar a eficiência das duas espécies vegetais quanto à inibição do radical DPPH (Desmachelier et al., 1998; Katalinic et al., 2004). No presente experimento (Figuras 1 e 2), é possível considerar que todas as preparações de droga vegetal (extratos, tinturas etc.) (Anvisa, 2004) obtidos de A. satureioides revelaram-se ligeiramente mais eficientes

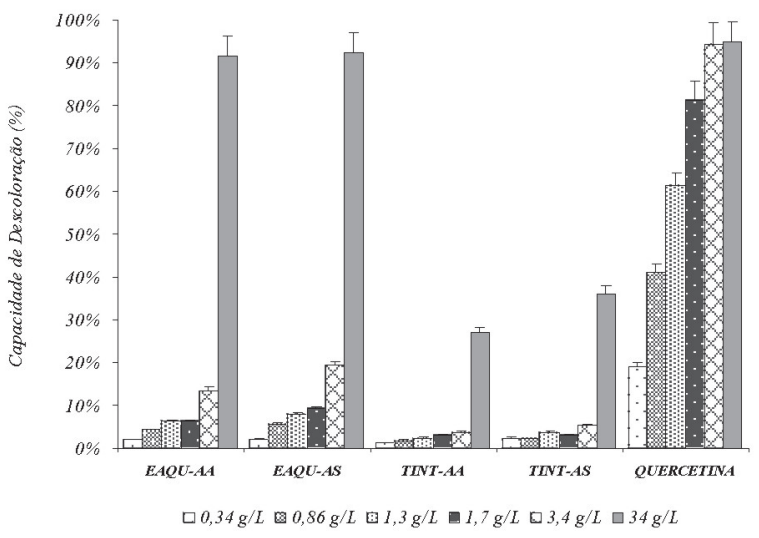

Figura 1. Avaliação da atividade captora de radicais DPPH, medida pela capacidade de descoloração, de diferentes derivados de droga vegetal (extrato aquoso liofilizado, EAQU, e tintura, TINT) obtidos de inflorescências de Achyrocline alata (AA) e Achyrocline satureioides (AS) - Asteraceae, em comparação com o padrão quercetina. que os da espécie sucedânea (A. alata), principalmente na concentração mais alta. Somente os extratos aquosos, nas maiores concentrações e para ambas as espécies, é que se apresentaram semelhantes quanto à atividade inibidora de DPPH. Esta última observação é relevante, uma vez que essa forma de utilização da planta medicinal é a mais disseminada na medicina popular regional, o que poderia justificar o hábito regional de substituir a "macela" pelo “jateí-kaá” (Nunes et. al., 2003).

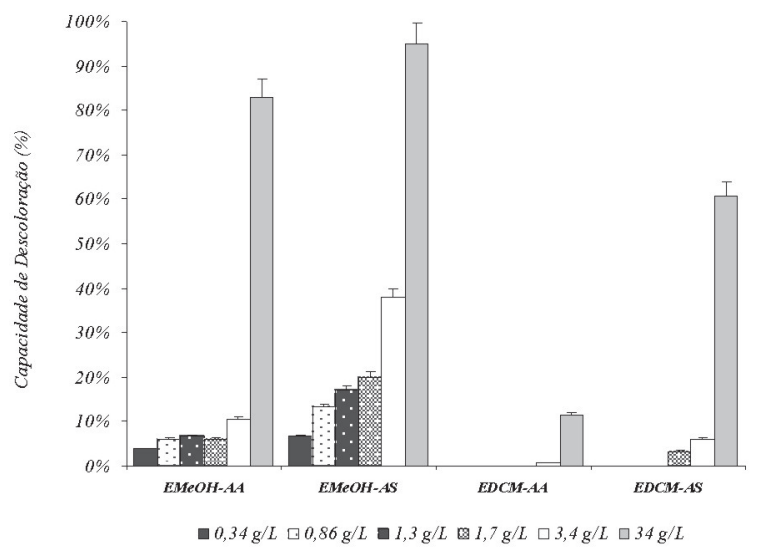

Figura 2. Avaliação da atividade captora de radicais DPPH, medida pela capacidade de descoloração, de diferentes extratos (extrato metanólico, $E M e O H$, e extrato diclorometânico, $E D C M$ ) obtidos das inflorescências de Achyrocline alata (AA) e Achyrocline satureioides (AS) - Asteraceae.

Nenhuma das espécies mostrou-se tão eficiente quanto a substância-padrão na inibição do radical-DPPH, o que pode ser justificado pela diversidade química de um extrato ou de qualquer outra preparação de droga vegetal em comparação a uma substância reconhecidamente ativa (Pietta, 2000). Apesar de ambas as espécies conterem flavonóides e estes, reconhecidamente, serem bons exemplos de princípios ativos antioxidantes, o padrão de substituição, o tipo de esqueleto de flavonóide presente e o teor de um extrato são variáveis que devem ser levadas em consideração.

\section{DISCUSSÃO}

Há diferentes modelos para avaliação da atividade captora de radicais e da atividade antioxidante, principalmente envolvendo reações quimicas in vitro. No presente trabalho, os modelos utilizados são ensaios químicos in vitro, de baixo custo, simples, rápidos e com boa reprodutibilidade para a pesquisa de novos compostos antioxidantes e captores de radicais livres (Ioset et al., 2001; Vicentino \& Menezes, 2007; Nunes et al., 2008; Morais et al., 2009).

A participação de reações envolvendo a produção de radicais livres em diferentes processos patológicos (Gordon 1996; Cao \& Li, 2004; Dasgupta et al., 2004) e na defesa do organismo (Gordon, 1996; Stosic-Grupicic et al., 
2004) tem sido discutida, bem como o aumento de radicais em algumas organelas, devido a algum desequilíbrio que pode ser danoso ao sistema biológico. As metodologias acima mencionadas visam confirmar as atividades de substâncias naturais e extratos vegetais que freqüentemente não estão presentes in loco em organelas vitais de um sistema biológico (Gordon, 1996; Pietta, 2000), mas que, de outra forma, podem ser associada indiretamente à defesa dessas organelas frente a um ataque por espécies ativas de oxigênio ou por qualquer outro radical produzido durante o estresse oxidativo (Gordon, 1996; Pietta, 2000).

Apesar dessa distinção entre os tipos de substâncias encontradas in vivo e in loco (Gordon, 1996) e dos metabólitos secundários testados nos modelos in vitro, é bastante difundido o hábito de inserção na dieta alimentar de alimentos ricos em substâncias com propriedade antioxidante. De maneira semelhante a utilização preventiva de produtos medicamentosos antioxidantes é frequentemente sugerida, uma vez que diferentes substâncias naturais (Pietta, 2000) e extratos vegetais apresentam atividade captora e/ou inibidora de radicais livres e de espécies reativas de oxigênio. Nisso destacam-se as substâncias fenólicas, como por exemplo os flavonóides (Gordon, 1996; Pietta, 2000; Donatini et al., 2009), havendo evidências epidemiológicas para tal consideração (Pietta, 2000, Katalinic et al., 2004).

Essa constatação poderia justificar o uso popular de $A$. alata e A. satureioides em diferentes processos patológicos que envolvem processos inflamatório e infeccioso, uso este já apontado em outro estudo (Nunes et al., 2003), uma vez que a presença de diferentes tipos de flavonóides e outras substâncias fenólicas foi constatada na constituição química de ambas as espécies (Broussalis et al., 1988; 1993; Bohlmann et al., 1980). Por sua vez, o uso popular predominante de extratos aquosos, pela constatação (Figura 1) de que em suas maiores concentrações eles apresentaram, dentro do modelo utilizado, atividades semelhantes em ambas as espécies, o que corrobora o fato de serem utilizados indistintamente.

\section{AGRADECIMENTOS}

À Professora Lílian Auler Mentz, pela identificação botânica. Ao PIBIC-CNPq-UFMS, pelas bolsas de iniciação científica, e à FUNDECT-MS, pelo apoio financeiro.

\section{REFERÊNCIAS}

Anvisa 2004. Agência Nacional de Vigilância Sanitária - ANVISA. Resolução RDC n. ${ }^{\circ}$ 48, de 16 de março de 2004. Dispõe sobre o registro de medicamentos fitoterápicos. Diário Oficial da União, 18/03/ 2004.

Bohlmann F, Abraham WR, Robinson H, King, RM 1980. A new labdane derivative and geranylphloroglucinols from Achyrocline alata. Phytochemistry 19: 2475-2477.
Bouhcet N, Barrier L, Fauchoneau B 1998. Radical scavenging activity and antioxidant properties of tannins from Guiera senegalensis (Combretaceae). Phytother Res 12: 159-62.

Braca A, Sortino C, Politi M, Morelli I, Mendez J 2002. Antioxidant activity of flavonoids from Licania licaniaeflora. $J$ Ethnopharmacol 79: 379-381.

Bremer, K 1994. Asteraceae - Cladistics \& Classification. Portland (Oregon, USA): Timber Press.

Broussalis AM, Ferraro GE, Gurni A, Coussio JD 1988. Phenolic constituents of four Achyrocline species. Bioch Syst Ecol 16: 401-402.

Broussalis AM, Ferraro GE, Coussio JD 1993. Phenolic constituents of Achyrocline alata. Bioch Syst Ecol 21: 306-306.

Cao Z, Li Y 2004. The chemical inducibility of mouse cardiac antioxidants and phase 2 enzymes in vivo. Bioch Bioph Res Comm 317: 1080-1088.

Cavin A, Hostettmann K, Dyatmyro W, Potterat, O 1998a. Antioxidant and lipophilic constituents of Tinospora crispa. Planta Med 64: 393-396.

Cavin A, Potterat O, Wolfender J-L, Hostettmann, K, Dyatmyko, W 1998b. Use of on-flow LC/1H NMR for the study of an antioxidant fraction from Orophea enneandra and isolation of a polyacetylene, lignans, and a tocopherol derivative. J Nat Prod 61: 1497-1501.

Dasgupta T, Banerjee, S, Yadava PK, Rao AR 2004. Chemopreventive potential of Azadirachta indica (neem) leaf extract in murine carcinogenesis model systems. J Ethnopharmacol 92: 23-36.

De Siqueira 2002. O aparelho utilizado foi desenvolvido pelo autor do presente artigo. Informações adicionais podem ser obtidas na página www.farmacognosia.ufms.br ou pelo e-mail citado no presente artigo.

Desmachelier C, Coussio J, Cicia G 1998. Antioxidant and free radical scavenging effects in extracts of the medicinal herb Achyrocline satureioides (Lam.) DC. (marcela). Braz J Med Biol Res 31: 1163-1170.

Donatini RS, Ishikawa T, Barros SBM, Bacchi EM 2009. Atividades antiúlcera e antioxidante do extrato de folhas de Syzygium jambos (L.) Alston (Myrtaceae). Rev Bras Farmacogn 19: 89-94.

Fachinetto JM, Bagatini MD, Durigon J, Silva ACF, Tedesco SB 2007. Efeito anti-proliferativo das infusões de Achyrocline satureioides DC (Asteraceae) sobre o ciclo celular de Allium cepa. Rev Bras Farmacogn 17: 49-54.

Farmacopéia Brasileira 1988. 4. ed. São Paulo: Atheneu. Parte 1.

Gordon MH 1996. Dietary antioxidants in disease prevention. Nat Prod Rep 13: 265-273.

Ioset JR, Marston A, Gupta MP, Hostettmann K 2001. A methylflavan with free radical scavenging properties from Pancratium littorale. Fitoterapia 72: 35-39.

Kadarian C, Broussalis AM, Miño J, Lopes P, Gorzalczany S, Ferraro G, Acevedo C 2002. Hepatoprotective activity of Achyrocline satureoides (Lam.) DC. Pharm Res 45: 57-60. 
Katalinic V, Milos M, Modun D, Music I, Boban M 2004. Antioxidant effectiveness of selected wines in comparison with (+)-catechin. Food Chem 86:593-00.???

Lemos-Senna EMT, Petrovick PR, Ortega GG 1997. Preparation and characterization of spray-dried powders from Achyrocline satureioides (Lam.) DC extracts. Phytother Res 11: 123-1237.

Mariath IR, Falcão HS, Barbosa-Filho JM, Sousa LCF, Tomaz ACA, Batista LM, Diniz MFFM, Athayde-Filho PF, Tavares JF, Silva MS, Cunha EVL 2009. Plants of the American continent with antimalarial activity. Rev Bras Farmacogn 19: 158-192.

Morais SM, Cavalcanti ESB, Costa SMO, Aguiar LA 2009. Ação antioxidante de chás e condimentos de grande consumo no Brasil. Rev Bras Farmacogn 19: 315-320.

Nunes GP, Silva MF, Resende UM, Siqueira JM 2003. Plantas medicinais comercializadas por raizeiros no centro de Campo Grande, Mato Grosso do Sul. Rev Bras Farmacogn 13: 83-92.

Nunes XP, Mesquita RF, Silva DA, Lira DP, Costa VCO, Silva MVB, Xavier AL, Diniz MFFM, Agra MF 2008. Constituintes químicos, avaliação das atividades citotóxica e antioxidante de Mimosa paraibana Barneby (Mimosaceae). Rev Bras Farmacogn 18 (Supl): 718-723.

Pietta PG 2000. Flavonoids as antioxidants. J Nat Prod 63:103542.

Pryor W 1986. Introdução ao estudo dos radicais livres. São Paulo: EdUSP.

Simoes CMO, Schenckel EP, Bauer L, Langeloh A 1988. Pharmacological investigations on Achyrocline satureioides (Lam.) DC. Compositae. J Ethnopharmacol 22: 281293.

Sonaglio D 1987. Padronização de extrato hidroalcoólico das sumidades floridas de Achyrocline satureioides (Lam.) DC., Compositae (marcela). Porto Alegre, 185p. Dissertação de Mestrado Faculdade de Farmácia - Universidade Federal do Rio Grande do Sul.

Souza, KCB de 2002. Avaliação biológica de preparações obtidas das inflorescências de Achyrocline satureioides (Lam.) DC. (marcela). Porto Alegre, 235p. Tese de Doutorado - Faculdade de Farmácia - Universidade Federal do Rio Grande do Sul.

Stosic-Grujicic, SD, Miljkovic DM, Cvetkovic ID, MaksimovicIvanic DD, Trajkovic V 2004. Immunosuppressive and anti-inflammatory action of antioxidants in rat autoimmune diabetes. J Autoimm 22: 267-276.

Vendruscolo GS, Rates SMK, Mentz LA 2005. Dados químicos e farmacológicos sobre as plantas utilizadas como medicinais pela comunidade do bairro Ponta Grossa, Porto Alegre, Rio Grande do Sul. Rev Bras Farmacogn 15: 361-372.

Vicentino ARR, Menezes FS 2007. Atividade antioxidante de tinturas vegetais, vendidas em farmácias com manipulação e indicadas para diversos tipos de doenças pela metodologia do DPPH. Rev Bras Farmacogn 17: 384-387. 